\title{
The significance of traumatic haematoma in the region of the basal ganglia
}

\author{
P MACPHERSON, E TEASDALE, S DHAKER, G ALLERDYCE, S GALBRAITH \\ From the Departments of Neuroradiology and Neurosurgery, Institute of Neurological Sciences, Southern
General Hospital, Glasgow, UK
}

SUMMARY Computed tomography demonstrated a haematoma in the region of the basal ganglia in 61 of 2000 head injured patients. In 41 the haematoma occurred as an isolated lesion while in 20 there was another associated intracranial haematoma. Clinical and radiological differences within these groups are discussed. The patients with basal ganglia haematoma were more severely injured than those in a group who had an intracranial haematoma evacuated by craniotomy and the findings closely resembled those of a group of patients who had sustained diffuse brain damage. They share many features with those of patients with diffuse white matter injury and have a worse prognosis than other traumatic intracranial haematomas.

Computed tomography (CT) has proved to be of enormous value in the assessment of traumatic intracranial haematomas and has led to improved clinical management with significant reductions in morbidity and mortality. ${ }^{1}$ CT also demonstrates the effects of diffuse brain injury, though unfortunately the outcome for patients shown to have suffered this type of damage has not been similarly improved. It is only since the advent of CT that one has been able to identify in life small haematomas in the region of the basal ganglia. Basal ganglia haematomas were infrequently described before the scanning era $^{2}$ and most reports since have concerned very large lesions. ${ }^{3}$ This study investigates the cause of injury, the clinical features, the CT appearances, and the outcome of a series of patients with basal ganglia haematoma, and considers the possible mechanisms responsible for these haematomas. It also assesses how the features of this group compare with those in a surgically treated group of patients with traumatic intracranial haematoma, and with a group of patients who sustained diffuse brain injury.

\footnotetext{
Address for reprint requests: Dr P Macpherson, Department of Neuroradiology, Institute of Neurological Sciences, Southern General Hospital, Glasgow G51 4TF, UK.
}

Received 12 February 1985 and in revised form 26 April 1985. Accepted 10 May 1985

\section{Patients and methods}

The regional Neurosurgical Unit of the Institute of Neurological Sciences, Glasgow serves a population of 2.7 million. It admits all head injured patients within the region who are confused, have focal signs or are in coma: approximately 500 per year. Only a minority (approximately $20 \%$ ) have an intracranial haematoma.

The scans of 2000 of the head injured patients admitted during the period 1979-1983 were reviewed retrospectively by one of us (PM) and 61 were found to have a haematoma in the basal ganglia region. These patients were then sub-divided into a group in which the basal ganglia haematoma occurred as an isolated lesion (41) and one in which the haematoma was associated with another intracranial haematoma (20). The former group were further sub-divided by CT appearances into those with normal intracranial pressure (20) and those with evidence of raised intracranial pressure (18); that is presence or absence of the 3 rd ventricle with or without absent basal cisterns, such findings being consistent with an intracranial pressure of $>20 \mathrm{~mm} \mathrm{Hg}{ }^{4}$. Three patients had a large isolated basal ganglia haematoma causing midline displacement of $>5 \mathrm{~mm}$ with resulting direct ventricular compression, and were considered separately. In the associated group, the second haematoma was intracerebral in 11, subdural in five and extradural in four.

Clinical information concerning age, cause of accident, lucid intervals, focal signs and conscious levels (Glasgow Coma Scale ${ }^{5}$ ) were obtained from a retrospective analysis of the case records and this information transferred to a computer sheet. Details of skull fracture had been noted at the time of admission by the neuroradiologist who had later analysed the CT scan. Haematoma size was calculated approximately by multiplying maximum length by the maximum width on the slice with the maximum dimensions and 


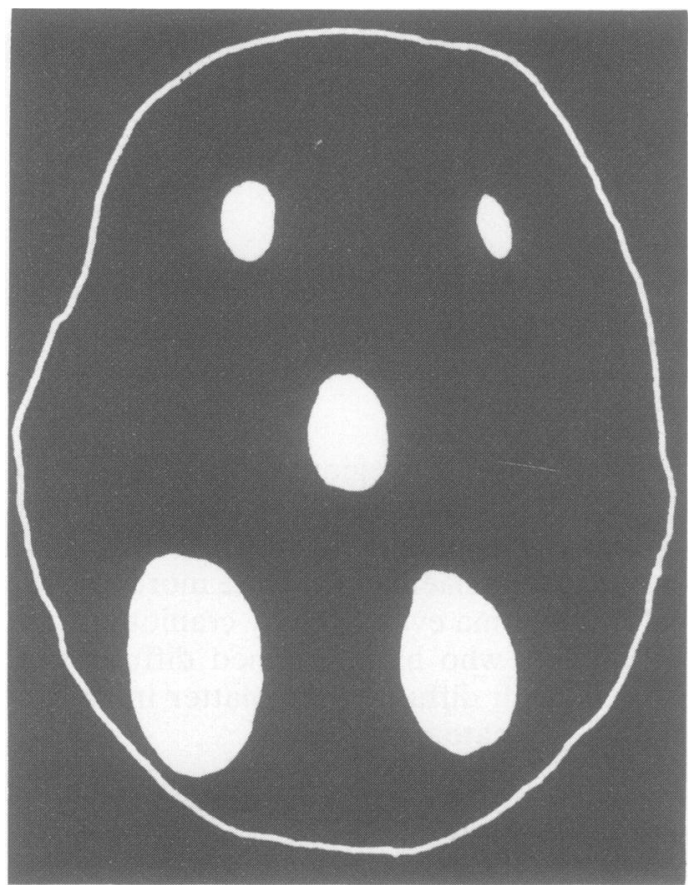

Fig 1 An outline of a CT head scan showing the relative size of a haematoma in each of the five grades of the haematoma index.

then corrected for magnification and the results used to give a "haematoma index" of five grades. Grade $1=1-$ $100 ; 2=101-300 ; 3=301-600 ; 4=601-1200 ; 5=$ $>1200$ (fig 1). Outcome was assessed at 6 months using the Glasgow Outcome Scale. ${ }^{\circ}$

The 61 basal ganglia haematoma patients form the basis of the study, but in order to assess their relationship to other head injured patients they have been compared with two other well defined groups identified in Glasgow in the years 1978-80, the years nearest to the basal ganglia haematoma population for which complete information was available. Firstly, a haematoma group which comprised those patients with a traumatic intracranial haematoma evacuated at craniotomy.' Secondly, a diffuse injury group of patients who were in coma (no eye opening, verbal responses no greater than incomprehensible sounds and not obeying commands), as the result of head injury but without a mass lesion, collected as part of an international survey.

\section{Results}

Details of age, type of injury, clinical state and fracture for the various sub-groups are given in table 1 . Age incidence In the isolated group those without evidence of raised intracranial pressure had a mean age of 32 years while those with evidence of raised pressure were significantly younger, having a mean age of 18 years $(p \sim 0.035)$. The mean age of the total isolated group was 26 years while that in the associated group was significantly higher at 43.5 (p $<0.01$ ).

Cause of accident Eighty-three per cent of those with isolated haematomas were traffic accident victims, as were $45 \%$ in the associated group ( $\mathrm{p}<$ 0.001 ), giving an overall total of $69 \%$.

Clinical features Only one patient from the total group had a lucid interval and $84 \%$ of the patients were in coma on admission to the local hospital. Clinical features of localised neurological dysfunction were present in 16 of the 41 patients $(39 \%)$ in the isolated group. In 11 , the basal ganglia haematoma was on the contralateral side, in three ipsilateral and it was bilateral in two. Localised features were present in 10 of the 20 patients with associated haematoma. In four, the basal ganglia haematoma was on the contralateral side, being ipsilateral in the other six. In three of the latter, the associated haematoma was contralateral to the basal ganglia haematoma.

Skull fracture was detected radiographically in 28 of the 61 patients $(46 \%)$ in comparable proportions in the isolated and associated groups. In 24 , the fracture involved the lateral aspect of the skull and of these the basal ganglia haematoma was contralateral

Table 1 Comparison of findings in the basal ganglia haematoma subgroups

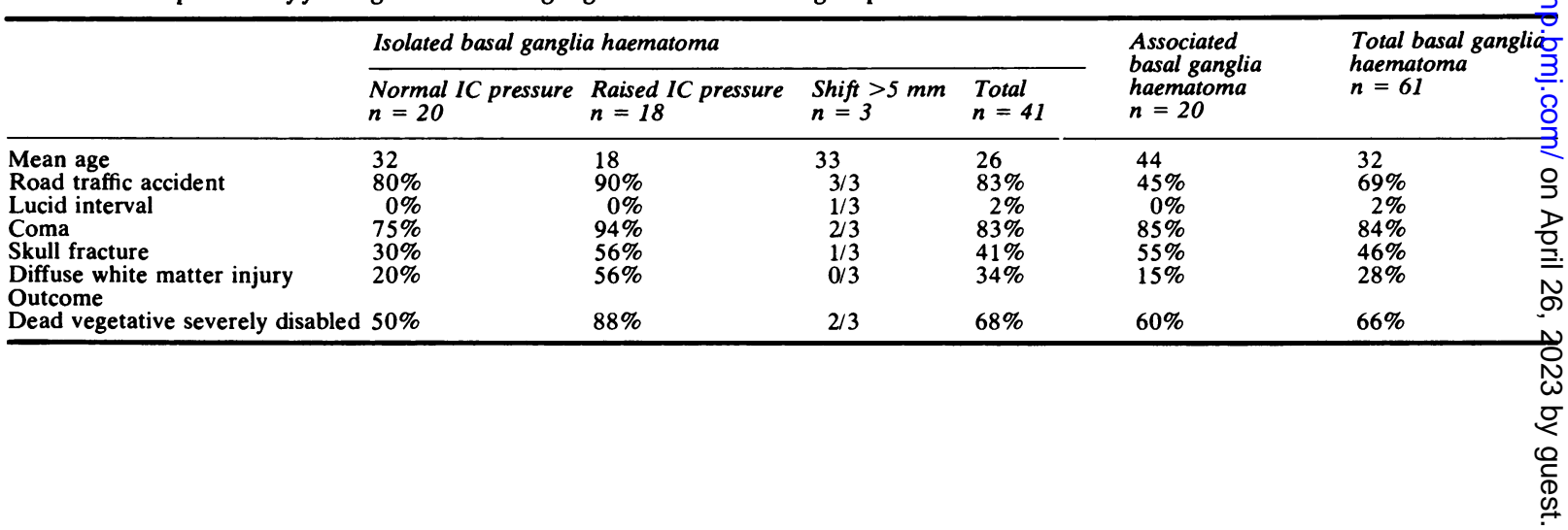


Table 2 Haematoma size related to time from injury to $C T$

\begin{tabular}{cl}
\hline Time from injury to $C T(h)$ & Haematoma index mean size \\
\hline $1-3(n=10)$ & $2 \cdot 9$ \\
$3-6(n=9)$ & $2 \cdot 1$ \\
$6-12(n=18)$ & $2 \cdot 2$ \\
$12-24(n=10)$ & $2 \cdot 4$ \\
$24-72(n=6)$ & $2 \cdot 5$ \\
$>72(n=1)$ & 1 \\
Information missing $(\mathrm{n}=7)$ & \\
\hline
\end{tabular}

to the fracture in $17(71 \%)$, ipsilateral in six $(25 \%)$ and bilateral in one $(4 \%)$. A contralateral fracture was therefore significantly more common than an ipsilateral fracture $(\mathrm{p} \sim 0.02)$.

$C T$ findings Of the 54 patients in whom the time from injury to CT is known, $37(68.5 \%)$ were scanned within 12 hours and $47(87 \%)$ within 24 hours. The mean time intervals from injury to $\mathrm{CT}$ were comparable in the isolated and associated groups. The haematoma index placed 11 of the $41(27 \%)$ of the isolated haematomas into grades $4-5$ as opposed to 3 of the $20(15 \%)$ in the associated group. The mean size was not found to be influenced by the time from injury to CT (Table 2).

The associated intracerebral and subdural haematomas were almost equally ipsi or contralateral to the basal ganglia haematomas while the four extradural haematomas were all contralateral to the basal ganglia haematomas.

Diffuse primary white matter injury was considered to be present when a haematoma was demonstrated in the corpus callosum, cerebellar peduncle or in the ventricles in the absence of a juxta ventricular haematoma. ${ }^{8}$ Such abnormalities were found in $56 \%$ of the isolated group with raised intracranial pressure; overall in $34 \%$ of the isolated group, but in only $15 \%$ of the associated group. Midline shift of $>5 \mathrm{~mm}$ was present in $12 / 20$ of the associated haematoma group and in only $3 / 41$ of the isolated group.

Outcome Overall $68 \%$ of the isolated and $60 \%$ of the associated basal ganglia haematoma patients were either dead, vegatative or severely disabled at 6 months. The poorest outcome occurred in the iso-

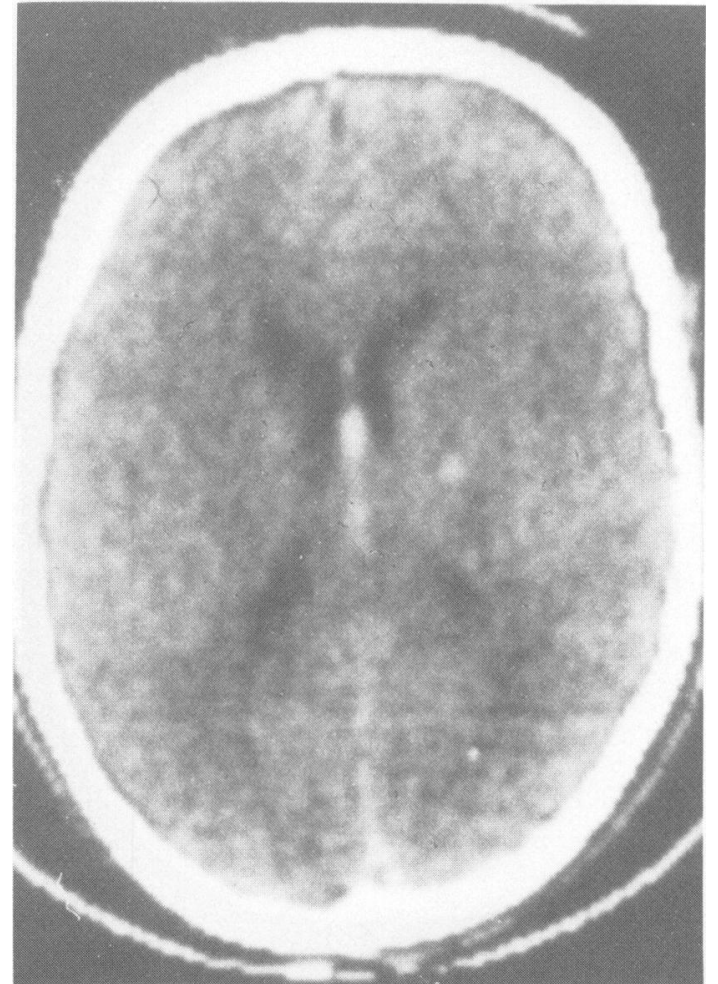

Fig 2 CT scan showing haematoma in the region of the right basal ganglia and in the corpus callosum (aged 16; road traffic accident; severely disabled).

lated group with raised intracranial pressure of whom $88 \%$ fell into the above categories. Of those who remained severely disabled, the disability was both physical and mental in the majority of patients. A movement disorder suggestive of basal ganglia dysfunction has persisted in only one patient.

Of those we were able to scan again after the acute phase, all had evidence of residual damage; cerebromalacia (fig 2), atrophy (fig 3 ) or hydrocephalus.

Table 3 Comparison of findings between the basal ganglia haematoma group and two other head injury groups

\begin{tabular}{|c|c|c|c|c|c|}
\hline & \multicolumn{3}{|c|}{ Basal ganglia haematoma } & \multirow{2}{*}{$\begin{array}{l}\text { Operated haematoma } \\
\text { group } n=378\end{array}$} & \multirow{2}{*}{$\begin{array}{l}\text { Diffuse injury group } \\
n=501\end{array}$} \\
\hline & $\begin{array}{l}\text { lsolated } \\
n=41\end{array}$ & $\begin{array}{l}\text { Associated } \\
n=20\end{array}$ & $\begin{array}{l}\text { Total } \\
n=61\end{array}$ & & \\
\hline $\begin{array}{l}\text { Mean age } \\
\text { Road traffic accident } \\
\text { No lucid interval } \\
\text { Coma } \\
\text { Skull fracture } \\
\text { Outcome }\end{array}$ & $\begin{array}{l}26 \\
83 \% \\
98 \% \\
83 \% \\
41 \%\end{array}$ & $\begin{array}{r}44 \\
45 \% \\
100 \% \\
85 \% \\
55 \%\end{array}$ & $\begin{array}{l}33 \\
69 \% \\
98 \% \\
84 \% \\
46 \%\end{array}$ & $\begin{array}{l}43 \\
25 \% \\
38 \% \\
42 \% \\
71 \%\end{array}$ & $\begin{array}{l}37 \\
55 \% \\
77 \% \\
75 \% \\
43 \%\end{array}$ \\
\hline $\begin{array}{l}\text { Dead, vegetative severely } \\
\text { disabled }\end{array}$ & $68 \%$ & $60 \%$ & $66 \%$ & $46 \%$ & $65 \%$ \\
\hline
\end{tabular}



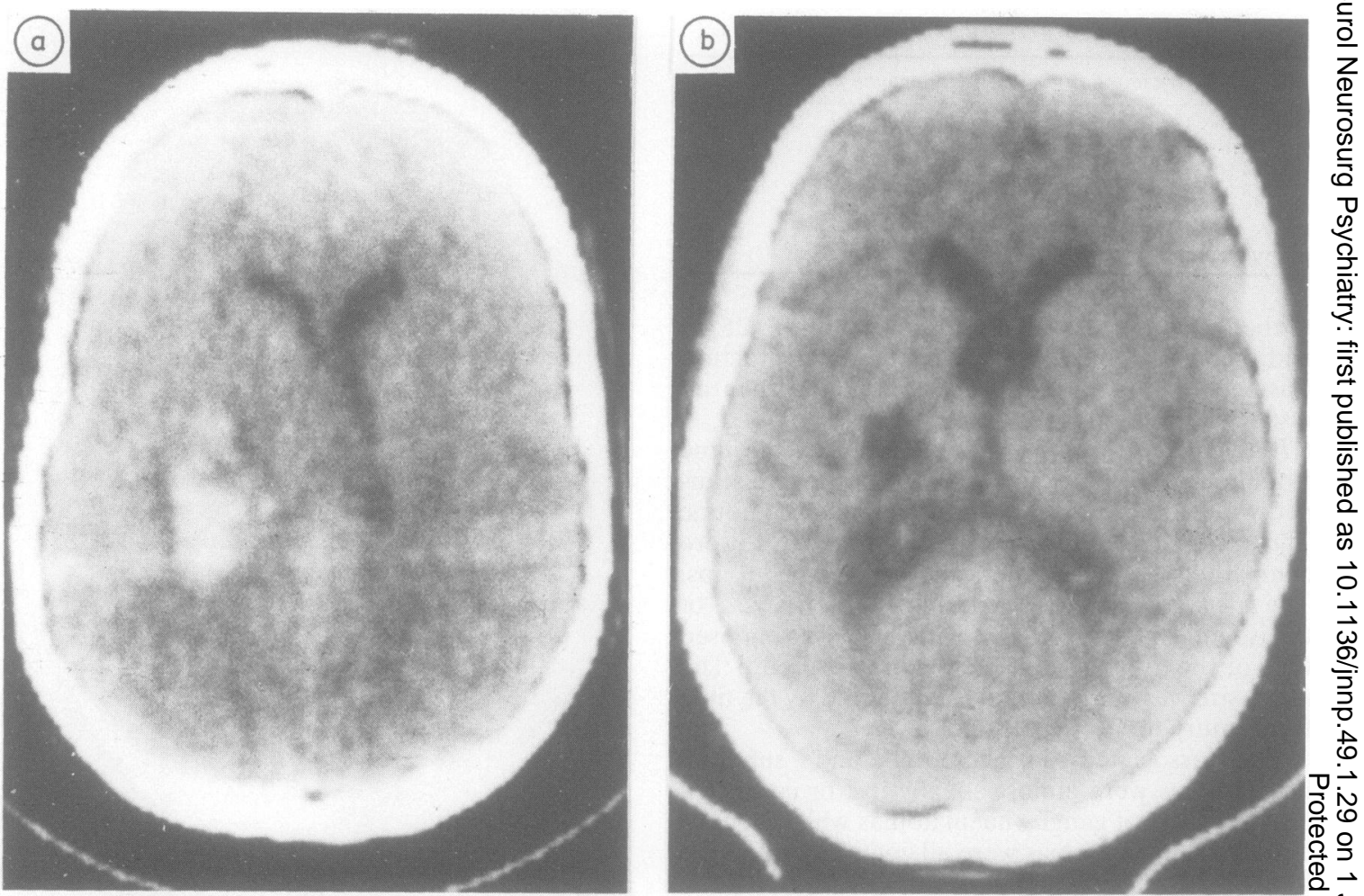

Fig 3 (a) Left sided basal ganglia haematoma. (b) Subsequent cerebro malacia (aged 16; road traffic accident: severely disabled).
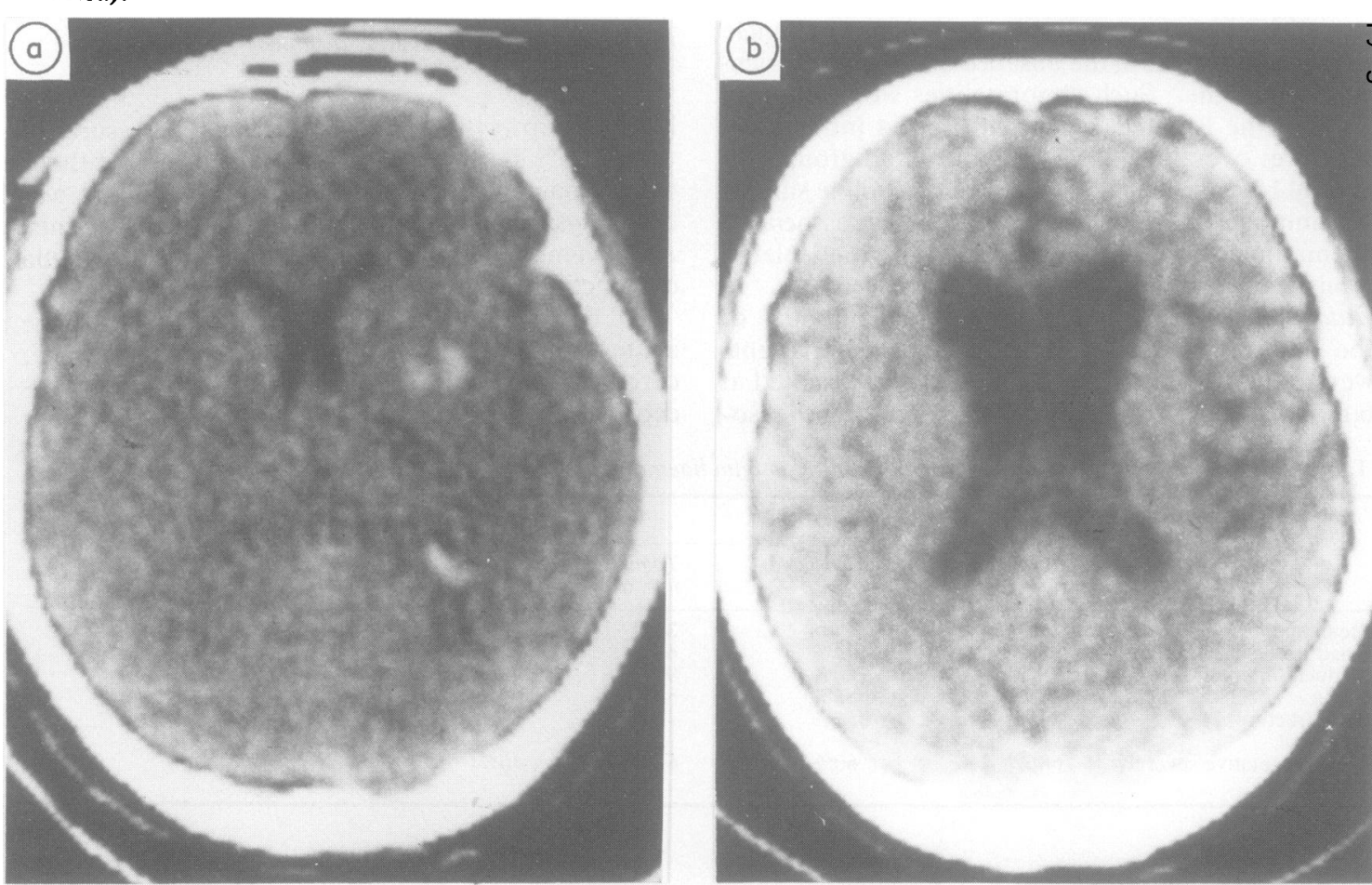

Fig 4 (a) Right sided basal ganglia haematoma. (b) Subsequent atrophy (aged 63; road traffic accident; severely disabled). 
Comparison with other head injured populations

The comparisons are summarised in table 3 .

When the basal ganglia haematoma group of patients was compared with the surgically treated group of intracranial haemaomas, then significant differences were found in all features considered: the patients in the former group were younger $(p<$ 0.01 ); a higher proportion had been involved in high velocity accidents $(p<0.001)$; they had more rarely had a lucid interval ( $p<0.001)$; they had more usually been in coma $(p<0.001)$; they had less frequently had a fracture $(p<0.001)$ but they had a worse outcome $(p<0 \cdot 01)$.

If the isolated basal ganglia haematoma group and the associated basal ganglia haematoma group are considered either separately or together and compared to the diffuse head injury group, then significant differences are found only in the type of injury $(p<0.05)$ and the frequency of lucid interval $(\mathrm{p}<0.001)$, the basal ganglia haematoma patients having more often been involved in a road traffic accident and less frequently had a lucid interval.

\section{Discussion}

This study showed a basal ganglia haematoma in 3\% of head injured patients undergoing CT scanning in our unit. The lesion is therefore not common even in the selected population of head injured patients transferred to a neurosurgical unit (approximately $4 \%$ of all patients admitted to hospital with head injury). The stimulus for this study was the realisation that a haematoma in the region of the basal ganglia might be a specific traumatic entity.

We were able on CT grounds to recognise four categories of patients; those with isolated basal ganglia haematomas with and without pressure or mass effect and those with a basal ganglia haematoma plus another usually larger and often surgically significant haematoma. The clinical features associated with these groups also differed.

We have found that within the isolated basal ganglia haematoma group, patients were significantly younger and had a worse outcome when there was evidence of raised intracranial pressure. Cerebral swelling is a well known complication of high velocity injury in young patient and their worse outcome may have been due to the secondary brain damage. However, CT evidence of diffuse white matter injury was also significantly more common in patients with raised pressure and this must have contributed to the poorer outcome and to the occurrence of raised pressure as a secondary event in some cases.

On comparing the isolated with the associated basal ganglia haematoma groups we found that the only significant difference was in the mechanism of injury, more in the isolated group having been involved in a road traffic accident. There are two basic mechanisms of head injury, namely, contact and acceleration/deceleration (inertia) ${ }^{9}$ and in most cases of head injury both mechanisms are operative. Strich ${ }^{10+1}$ described the pathology of diffuse white matter injury and recent work has been reviewed by Adams and Graham. ${ }^{12}$ Experimentally it has been shown that angular acceleration in the oblique or lateral plane produces diffuse white matter injury. ${ }^{13}$ In an analysis of fatal head injuries, patients with diffuse white matter injury had a lower incidence of skull fracture than those without diffuse white matter injury and the injuries were more commonly the. result of road traffic accidents than of falls. ${ }^{14}$ This is because the acceleration/deceleration effects are of longer duration in the former. It has, however, also been shown that diffuse white matter injury can be caused by a fall of greater than the person's own height. ${ }^{15}$

The possibility that the lesions were actually due to haemorrhage into regions of ischaemia has to be considered, in view of the high incidence of ischaemic damage found in fatal non-missile head injuries. ${ }^{16}$ However, most ischaemic damage can only be identified microscopically. Moreover, as $68.5 \%$ of our patients were scanned within 12 hours and $87 \%$ within 24 hours of injury, it is highly unlikely that the lesions demonstrated by CT were the result of ischaemia.

From the comparison with other head injured populations, patients with basal ganglia haematoma were more severely injured than those in the operated haematoma group but the features closely resembled those of patients in the diffuse injury group. Radiological evidence of primary diffuse white matter injury was present in about one-third of the basal ganglia haematoma patients. CT had been performed using $160 \times 160$ matrix and $1 \mathrm{~cm}$ thick sections, and it is probable that more lesions would have been identified had we been using a high resolution scanner and taking thinner sections.

On the basis of these findings we suggest that patients with basal ganglia haematoma form a specific sub-group within the head injured populations. They share many features with patients with severe diffuse white matter injury and we propose that they are the result of shearing of blood vessels in the white matter as a result of the angular acceleration/deceleration forces. On the other hand, not all patients with diffuse white matter injury have a basal ganglia haematoma and a basal ganglia haematoma can occur in the absence of severe white matter injury. The occurrence of a lucid interval is not consistent with severe primary white matter 
injury and, in fact, only one of our patients with basal ganglia haematoma was lucid at some time. Although some patients with basal ganglia haematoma also had surgically significant intracranial haematomas there was much less overlap in the features of these groups than occurred between the basal ganglia haematoma and the diffuse injury group.

Although a haematoma in the region of the basal ganglia is rarely large enough to have appreciable space occupying effect, it is evidence of a significant primary brain injury, and carries a worse prognosis than other post-traumatic intracranial haematomas.

We are grateful to Professors JH Adams and DI Graham for advice on the neuropathological aspects of this paper.

\section{References}

' Teasdale G, Galbraith S, Murray L, Ward P, Gentleman D, McKean M. Management of traumatic intracranial haematoma. Br Med J 1982;285:1695-7.

${ }^{2}$ Mosberg WH, Lindenberg R. Traumatic haemorrhage from the anterior choroidal artery. J Neurosurg 1959; 16:209-21.

${ }^{3}$ Shigemori M, Tokutomi T, Shirahama M, Hara K, Yamamoto F. Massive traumatic haematoma localized in the basal ganglia. Neurol Med Chir (Tokyo) 1981;21:697-900.

${ }^{4}$ Teasdale E, Cardosa E, Galbraith S, Teasdale G. CT Scan in severe diffuse head injury: physiological and clinical correlations. J Neurol Neurosurg Psychiatry 1984;47:600-3.

s Teasdale G, Jennett B. Assessment of coma and impaired consciousness. A practical scale. Lancet 1974;2:81-4.

6 Jennett B, Bond M. Assessment of outcome after severe brain damage. Lancet 1974; 1:480-4.

7 Jennett B, Teasdale G, Galbraith S, et al. Severe head injuries in three countries. J Neurol Neurosurg Psychiatry 1977;40:291-8.

${ }^{8}$ Zimmerman RA, Bilaniuk LT, Gennarelli T. Computed tomography of shearing injuries of the cerebral white matter. Radiology 1978;127:393-6.

' Ommaya AK, Gennarelli TA. Cerebral concussion and traumatic unconsciousness. Correlation of experimental and clinical observations on blunt head injuries. Brain 1974;97:633-54.

${ }^{10}$ Strich SJ. Diffuse degeneration of the cerebral white matter in severe dementia following head injury. $J$ Neurol Neurosurg Psychiatry 1956;19:163-85.

"Strich SJ. Shearing of nerve fibres as a cause of brain damage due to head injury. Lancet 1961;2:443-8.

12 Adams JH, Graham DI. Diffuse brain damage in nonmissile head injury. In: Anthony PP, Macsween RNM, eds. Recent Advances in Histopathology. Edinburgh: Churchill Livingstone, 1984:241-57.

${ }^{13}$ Gennarelli TA, Thibault LE, Adams JH, Graham DI, Thompson CJ, Marcincin RP. Diffuse axonal injury and traumatic coma in the primate. Ann Neurol 1982;12:564-74.

${ }^{14}$ Adams JH, Graham DI, Murray LS, Scott G. Diffuse axonal injury due to non-missile head injury in humans: an analysis of 45 cases. Ann Neurol 1982;12:557-63.

is Adams JH, Graham DI, Doyle D, Lawrence AE, McLellan DR. Diffuse axonal injury in head injuries caused by a fall. Lancet $1984 ; 2: 1420-1$.

${ }^{16}$ Graham DI, Adams JH, Doyle D. Ischaemic brain damage in fatal non-missile head injuries. $J$ Neurol Sci 1978;39:213-34. 